д-р техн. наук Греков С.П. / Grekov S.P., Ph.D. ${ }^{1}$

проф. д-р техн. наук Пашковский П.C. / prof. Pashkovskiy P.S., Ph.D.

инж. Орликова В.П. / Orlikova V.P., Eng.

Przyjęty/Accepted/Принята: 06.04.2015;

Zrecenzowany/Reviewed/Рецензирована: 20.08.2015;

Opublikowany/Published/Опубликована: 30.09.2015;

\title{
Определение температуры самонагревания угля по соотношению оксида углерода и убыли кислорода на аварийном участке ${ }^{2}$
}

\author{
Identification of Temperature for Self Heating of Coal Caused by the Ratio of Carbon \\ Oxide and Decreasing Oxygen Levels Along a Section Exposed to a Catastrophe
}

\author{
Określenie temperatury samonagrzewania się węgla w zależności od zawartości \\ tlenku węgla i ubytku tlenu na odcinku awaryjnym
}

\begin{abstract}
АННОТАЦИЯ
Цель: Целью исследований является расчет температуры самонагревания угля по соотношению оксида углерода и убыли кислорода на аварийном участке.

Актуальность: Актуальность исследований обусловлена длительностью используемого на практике метода определения температуры угля по отношению содержания непредельных углеводородов и необходимостью разработки экспресс - метода получения данных об эндогенном пожаре для принятия мер по его тушению.

Методы: Основаны на теоретической модели неизотермической кинетики гетерогенного окисления углей с переменной реакционной поверхностью кислородом воздуха, что вызвано метановыделением из угля, а также образованием и распадом поверхностных соединений при адсорбции кислорода и образовании вблизи поверхности частиц твердых продуктов реакции. Результаты: Предложена математическая модель процесса самонагревания в слое угля как пористой среде. Полагалось, что поступающий в такой слой фильтрационный поток воздуха, содержащий кислород, вступает в химические реакции окисления, что порождает источники тепла. Выделяющееся тепло расходуется на передачу через поверхность, ограничивающую слой угля и повышение его температуры.

Получено аналитическое решение задачи. Для описания интенсивности тепловыделения использована ранее разработанная авторами математическая модель. Учитывается изменение содержания кислорода и реакционной поверхности по мере окисления угля. Проанализировано около 30 экспериментов по определению удельной реакционной поверхности угля и получена ее зависимость от степени метаморфизма угля. Предложена зависимость для определения доли кислорода, вступающего в реакции окисления угля, и с учетом этого дана зависимость для вычисления интенсивности выделения тепла, его стока и температуры, зависимость от расхода кислорода на окисление угля. Предложена зависимость для определения температуры угля по соотношению оксида углерода и убыли кислорода на аварийном участке в результате его окисления углем. На конкретных примерах аварий на шахтах Донбасса показана возможность определения температуры самонагревания угля по данным анализа воздуха аварийного участка.

Практическая значимость: Полученные зависимости рекомендуются для опытно-промышленного использования контроля температуры самонагревания угля.

Выводы: Предложена математическая модель самонагревания в слое угля как пористой среде, апробированная на экспериментах НИИГД (Украины) и ФРГ в диапазоне температур 340-400 К на углях разной степени углефикации. Предложено использовать для определения температуры угля отношение оксида углерода к израсходованному на реакции окисления кислороду. Показано полное соответствие полученных результатов вычисления температуры с данными по соотношению этилена и ацетилена.
\end{abstract}

\footnotetext{
Научно-исследовательский институт горноспасательного дела и пожарной безопасности „Респиратор”, Украина / Тhe Respirator Scientific Research Institute of Mine-Work and Fire Safety, Donetsk, Ukraine; niigd@mail.ru;

2 Процентное участие в создании статьи / Percentage contribution: Grekov S.P. - 35\%, Pashkovskiy P.S. - 35\%, Orlikova V.P. $-30 \%$;
} 
Ключевые слова: гетерогенный процесс, доля реакционной поверхности, низкотемпературное окисление, скорость реакции, энергия активации, самовозгорание

Вид статьи: предварительный отчет

\section{A BS TRACT}

Aim: The purpose of this study is to determine the temperature for self heating of coal, caused by the ratio of carbon monoxide and decreasing oxygen levels along a mining section exposed to a catastrophe.

Introduction: The need for this study is associated with existing cumbersome methods used to determine the temperature of coal containing unsaturated hydrocarbons and necessity to identify a faster method for obtaining data about spontaneous fires, to facilitate the selection of appropriate firefighting measures.

Methods: Methods are based on the theoretical model for non-isothermic kinetics of heterogeneous oxidation of coal with a variable reactionary oxygen surface, caused by the release of methane, as well as by formation and decay of surface compounds through oxygen adsorption and formation of stable particles.

Results: A self heating model was put forward for a layer of coal, based on a representation involving a porous substance. It was assumed that a stream of filtered air, containing oxygen, oxidised upon entering such a layer and generated a heat source. Heat was absorbed across the coal surface culminating in an increase to its temperature. An analytical solution was obtained for this exercise. To describe the intensity of generated heat, the authors utilised their own, previously developed mathematical model. The model took into account the change in oxygen content and surface reaction, depending on coal oxidation levels. Some 30 experiments were performed and analysed, which addressed the issue of coal surface reaction and identified the relationship between the surface layer and degree of coal metamorphosis. This relationship was utilised to determine the proportion of oxygen absorbed during oxidation of coal. By taking account of such data it is possible to calculate the intensity of generated heat, its flow and temperature, and consequential use of oxygen during oxidation of coal. It is proposed that the ratio of carbon oxide to reduced oxygen levels along a section exposed to an emergency, as a result of oxidation can be used to determine coal temperature. This is illustrated by specific examples of mine incident analysis in the Donets Basin.

Practical benefit: The identified dependences are recommended for further research and industrial application with the aim of controlling the temperature of self heating coal.

Conclusions: The mathematical model for surface self heating of coal and porous substances, was approved during tests at NIIGD "Respirator" (Ukraine) and the Federal Republic of Germany, within the temperature range of 340-400 K, for use with different coal quality. It is proposed that the ratio of carbon oxide to oxygen used for oxidation reactions is utilized to determine the temperature of coal. Demonstrated full compatibility between derived results for temperature calculations and data concerning the ratio of ethylene to acetylene.

Keywords: heterogeneous process, surface reaction segment, low-temperature oxidation, reaction rate, activation energy, spontaneous combustion

Type of article: short scientific report

\section{A BSTRAKT}

Cel: Celem badań jest określenie temperatury samonagrzewania się węgla w zależności od zawartości tlenku węgla i ubytku tlenu na odcinku awaryjnym.

Aktualność badań: Potrzeba przeprowadzenia badań wiąże się z czasochłonnością wykorzystywanej dotychczas metody określenia temperatury węgla ze względu na zawartość węglowodorów nienasyconych oraz koniecznością opracowania szybkiej metody pozyskiwania danych na temat pożaru endogennego, które są niezbędne podczas wyboru odpowiednich środków do jego ugaszenia.

Metody: Metody opierały się na teoretycznym modelu nieizotermicznej kinetyki heterogenicznego utleniania tlenem z powietrza węgli ze zmienną (niejednorodną) powierzchnią reakcyjną, co powodowane jest wydzielaniem metanu z węgla, a także powstawaniem i rozpadem związków powierzchniowych przy adsorpcji tlenu i powstawaniu przy powierzchni stałych produktów reakcji.

Wyniki: W artykule zaproponowany został model procesu samonagrzewania się warstwy węgla na przykładzie środowiska porowatego. Założono, że wchodzący do takiej warstwy strumień filtrowanego powietrza wstępuje w reakcje chemiczne utleniania, przez co generowane jest źródło ciepła. Wydzielające się ciepło jest wydatkowane na przejście przez powierzchnię warstwy węgla i zwiększenie jego temperatury. Otrzymano rozwiązanie analityczne tego zadania. Do opisania intensywności wydzielania ciepła wykorzystano wcześniej opracowany przez autorów model matematyczny. Uwzględniono w nim zmianę zawartości tlenu i powierzchni reakcyjnej w miarę utleniania się węgla. Przeanalizowano około 30 eksperymentów polegających na określeniu powierzchni reakcyjnej węgla i otrzymano zależność między nią a stopniem metamorfizmu węgla. Zaproponowano wykorzystanie tej zależności do określenia zawartości procentowej tlenu wstępującego w reakcję utleniania węgla. Z uwzględnieniem tych danych możliwe jest wyliczenie: intensywności wydzielania ciepła, jego spadku i temperatury oraz zależności między zużyciem tlenu a utlenianiem się węgla. Autorzy przedstawili zależność, na podstawie której możliwe jest obliczenie temperatury węgla pod względem zawartości tlenku węgla i ubytku tlenu na odcinku awaryjnym. Na rzeczywistych przykładach awarii w kopalniach w Donbasie przedstawiono możliwość określenia temperatury samonagrzewania się węgla na podstawie danych analizy powietrza na odcinku awaryjnym.

Znaczenie dla praktyki: Otrzymane zależności są rekomendowane do badań i zastosowań przemysłowych w celu kontroli temperatury samonagrzewania się węgla.

Wnioski: Zaproponowany model matematyczny samonagrzewania się w warstwie węgla - środowisku porowatym - potwierdzony został w drodze eksperymentów przeprowadzonych przez Instytut Naukowo-Badawczy Górnictwa „Respirator” (Ukraina) i Republikę Federalną Niemiec w granicy temperatur 340-400 K na węglach o różnym stopniu uwęglenia. W celu określenia temperatury węgla 
zaproponowano wykorzystanie modelu opisującego stosunek zawartości tlenku węgla i tlenu biorącego udział w reakcjach utleniania. Wykazano pełną zgodność otrzymanych wyników wyliczeń temperatury z danymi w odniesieniu do etylenu i acetylenu.

Słowa kluczowe: proces heretogeniczny, udział/część powierzchni reakcyjnej, niskotemperaturowe utlenianie, szybkość reakcji, energia aktywacji, samonagrzewanie się

Typ artykułu: doniesienie wstępne

\section{1. Введение}

Эффективность борьбы с эндогенными пожарами, возникающими в выработанном пространстве угольных шахт, в значительной степени зависит от своевременности обнаружения и полноты информации о процессе самовозгорания угля. В процессе развития эндогенного пожара выделяют стадию самонагревания, раннюю стадию самовозгорания и стадию горения угля.

Самонагревание угля начинается, как только создаются условия для аккумуляции теплоты. Стадия самонагревания в основном определяет длительность инкубационного периода процесса самовозгорания и протекает в интервале температур, начиная со значений, характерных для условий данной выработки, и до критической температуры самовозгорания. По достижении критической температуры начинается ранняя стадия самовозгорания угля. Кроме изменения температуры в очаге пожара, происходят существенные изменения состава воздуха аварийного участка: уменьшается содержание кислорода, увеличивается выделение оксидов углерода, водорода, предельных и непредельных углеводородов, содержание которых значительно превышает фоновые значения. Признаком самонагревания угля на контролируемом участке является устойчивое превышение объемной доли СО и $\mathrm{H}_{2}$ над фоновым их содержанием. Однако по результатам определения превышения оксида углерода и водорода над фоновым их содержанием невозможно отличить стадию самонагревания от ранней стадии самовозгорания. Вместе с тем определение стадии развития эндогенного пожара имеет большое значение, поскольку ранняя стадия самовозгорания угля при благоприятных условиях может длиться всего несколько часов. Эти стадии на шахтах Украины определятся по температуре угля в очаге эндогенного пожара на основании данных о соотношении этилена $\mathrm{C}_{2} \mathrm{H}_{4}$ и ацетилена $\mathrm{C}_{2} \mathrm{H}_{2}$ в пробах воздуха аварийного участка, так как на стадии самонагревания и ранней стадии самовозгорания, вплоть до температуры воспламенения летучих веществ, рост доли этилена опережает рост доли ацетилена, вследствие чего соотношение этих компонентов закономерно увеличивается [1].

Известные методы оценки основаны на анализе продуктов реакции кислорода с углем, в то время как согласно теории «уголь-кислородного» комплекса на начальной стадии кислород физически сорбируется поверхностью угля с незначительным выделением теплоты. Затем с повышением температуры начинается расщепление неустойчивых кислородных комплексов с образованием конечных продуктов окисления угля
- оксидов углерода, воды, при котором выделение теплоты возрастает в 1,5-2 раза [2]. Таким образом, контроль концентрации кислорода дает возможность проследить весь процесс низкотемпературного окисления и, следовательно, является наиболее чувствительным индикатором раннего появления очага самонагревания угля.

Влияние содержания кислорода резко возрастает с повышением температуры: чем она выше, тем при меньшем содержании кислорода может протекать процесс окисления. Зависимость процесса самонагревания от содержания кислорода в шахтной среде является одним из главных факторов, влияющих на пожароопасность горных работ при переходе их на глубокие горизонты [3].

Между тем существующая система контроля на угольных шахтах, ограничивающаяся газовым анализом шахтной среды в действующих выработках и выработанном пространстве, зачастую оказывается малоэффективной при обнаружении самонагревания и практически не дает информации о местонахождении очага пожара. Отсутствие необходимой информации об эндогенном пожаре, особенно о местонахождении очага в выработанном пространстве, затрудняет использование активных методов тушения и становится причиной применения способа изоляции участков с признаками самонагревания.

Целью работы является разработка метода расчета температуры самонагревания угля по соотношению оксида углерода и убыли содержания кислорода на аварийном участке при эндогенном пожаре.

\section{2. Теоретические и экспериментальные исследования}

Ранее нами были рассмотрены тепловая и диффузионная задачи самонагревания угля, предполагая известными функциональные зависимости плотности источников и стоков от температуры и концентрации [4]. Сформулирована физическая и адекватная ей математическая модель процесса в слое различной толщины. Предложен способ численного решения задачи. Сложность вычислений и временами неадекватность полученного решения по разработанной программе из-за неустойчивости численного метода позволили нам предложить упрощенную математическую модель, позволяющую получить аналитическое решение задачи самонагревания угля в слое зернистого материала и его температуру.

Предполагается, что скопление угля, подверженное самонагреванию, - это некоторый минимальный объем, необходимый для развития процесса. Этот 
объем по данным автора [1] определяется минимальной толщиной его скопления $m$, которая составляет $0,14 \div 0,20$ м (на пласте $k_{8}^{\text {н }}$ при $m=0,19$ м произошло 8 пожаров, на пласте $l_{2}$ при $m=0,18$ м прошло 17 пожаров, на пласте $l_{7}$ при $m=0,14 \mathrm{M}-14$ пожаров).

Представим уравнение для динамика температуры в зоне самонагревания угля в виде:

$$
\rho c\left(\frac{\partial T}{\partial \tau}+u \frac{T-T_{0}}{l}\right)=\frac{\alpha \Pi}{S}\left(T_{c}-T\right)+q,
$$

где $\rho$ - плотность газа, кг/ $\mathrm{m}^{3}$;

$c$ - удельная теплоемкость газов при постоянном давлении, Дж/(кг.К);

$T$ - температура в очаге пожара, K;

$T_{0 \text { - }}$ температура до пожара, K;

$T_{\text {c }}$ - температура пород, окружающих скопление угля, К;

$u$ - скорость движения воздуха, м/с;

$l$ - длина зоны горения, м;

$\alpha$ - коэффициент теплообмена между скоплением угля и окружающими его породами,

$\mathrm{BT} /\left(\mathrm{M}^{2} \cdot \mathrm{K}\right)$;

П - периметр скопления угля, м;

$S$ - площадь поперечного сечения скопления угля, $\mathrm{M}^{2}$;

$q$ - интенсивность источника тепла при горении, Вт/м².

Для квазистационарного случая уравнение (1) примет вид:

$$
\tilde{u} \frac{T-T_{0}}{l}=\frac{\alpha \Pi}{\rho_{0} c S}\left(T_{c}-T\right)+\frac{q}{\rho_{0} c},
$$

где $\tilde{u}=\rho u / \rho_{0}-$ массовая скорость воздуха, м/с;

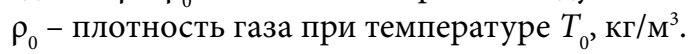

Принимая $T_{c}=T_{0}$ и решив уравнение (2) относительно температуры имеем

$$
T=T_{0}\left(1+\frac{\bar{q} l}{\widetilde{u}+\bar{\alpha}}\right)
$$

где: $\bar{\alpha}=\frac{\alpha \Pi l}{\rho_{0} c s}-$ удельный коэффициент теплообмена скопления угля с окружающими его породами, м/с;

$\bar{q}=\frac{q}{\rho_{0} c S}-$ удельная интенсивность тепловыделения в зоне горения, $1 / \mathrm{c}$.

Интенсивность тепловыделения в единице объема $q$ может быть представлена выражением [5]

$$
q=\frac{0,01\left(C_{0}-C_{1}\right) \widetilde{u} \rho_{0} H_{C}}{l},
$$

где $C_{0}$ - концентрация кислорода на входе в зону горения, \%;

$C_{1}$ - концентрация кислорода на выходе из зоны горения, \%;

$H_{\text {c }}$ - теплота сгорания твердого материала, Дж/кг.

Подставляя (4) в формулу (3), будем иметь

$$
T=T_{0}+\frac{0,01\left(C_{0}-C_{1}\right) \tilde{u} H_{c}}{c(\widetilde{u}-\bar{\alpha})} .
$$

Интенсивность тепловыделения $w_{q_{0}}$ согласно ранее предложенной математической модели [6], подтвержденной проведенными экспериментальными наблюдениями, может быть представлена в виде:

$$
\left.w_{q_{0}}=\xi a_{\mathrm{O}_{2}} a_{\mathrm{C}}^{*} k q_{0}, \text { Дж/( } \mathrm{m}^{3} \cdot \mathrm{c}\right),
$$

где $a_{\mathrm{O}_{2}}$ и $a_{\mathrm{C}}^{*}-$ концентрации кислорода и углерода, моль $/ \mathrm{M}^{3}$;

$k$ - константа скорости окисления, $\mathrm{M}^{3} /($ с-моль);

$\xi$ - доля концентрации кислорода, вступающего в реакции окисления с углем; $q_{0}$ - теплота реакции окисления, Дж/моль.

Здесь величина $\xi a_{\mathrm{O}_{2}}$ соответствует доле кислорода $\Delta C_{\mathrm{O}_{2}}=C_{0}-C_{1}, \%$, израсходованного на горение.

Примем во внимание, что при самонагревании угля скорость фильтрации воздуха через скопления угля мала, и первый член в скобках знаменателя $\tilde{u}$ выражения (5) на несколько порядков меньше чем $\bar{\alpha}$. Предположим, что при небольшом изменении температуры на начальной стадии самонагревания угля $\tilde{u}=u$. Тогда, приравнивая $w_{q_{0}} u q$ и подставляя (4) в (5), а также вместо $\bar{\alpha}$ используя его размерный вид, выражение (3) запишем в виде:

$$
T=T_{0}+\frac{w_{q_{0}} S}{\alpha \Pi}, \mathrm{K} .
$$

В работе [7] нами исследовалась скорость тепловыделения из углей с учетом предположения, что концентрация кислорода постоянна и равна единице. Выражение для скорости тепловыделения $v_{q_{0}}$, Дж/ (с·моль) имеет вид:

$$
v_{q_{0}}=q_{0} k
$$

где $q_{0}$ - теплота реакции окисления, Дж/моль, определяемая из выражения:

$$
q_{0}=6980 k^{-0,82}
$$

$k$ - константа скорости окисления угля, $1 /$ c.

С использование (9) выражение (8) примет вид:

$$
v_{\mathrm{q}_{0}}=6980 \mathrm{k}^{0,18} \text {. }
$$

Зависимость $v_{q_{0}}$ от концентрации горючих веществ в угле $V^{\mathrm{r}}$ в этой же работе представлена в виде:

$$
v_{q_{0}}=572\left(V^{\mathrm{T}}\right)^{0,5} .
$$

Объединяя (10) и (11) имеем:

$$
v_{q_{0}}=1322 k^{0,18}\left(V^{\Gamma}\right)^{0,5} .
$$

Выражение (12) можно записать в виде:

$$
v_{q_{0}}=1322\left(a_{\mathrm{C}}^{*} k\right)^{0,18}\left(V^{\mathrm{\Gamma}}\right)^{0,5},
$$

где $k$ - константа скорости окисления угля, $\mathbf{M}^{3} /($ с $\cdot$ моль).

При использовании зависимости концентрации углерода $a_{\mathrm{C}}^{*}$ от удельной поверхности угля $S_{\text {уд }} \mathrm{M}^{2} /$ кг, полученной в работе [6], выражение (13) запишем в виде:

$$
\begin{aligned}
v_{q_{0}} & =1322\left\{\left(-0,6 S_{\text {уд }}^{2}+235,8 S_{\text {уд }}+\right.\right. \\
& \left.\left.+9,1 \cdot 10^{4}\right) k\right\}^{0,18}\left(V^{\Gamma}\right)^{0,5} .
\end{aligned}
$$

Если учесть, что значение концентрации кислорода $a_{\mathrm{O}_{2} \text { в угле не равно } 1 \text { и изменяется по мере проникно- }}$ вения его вглубь угля, то используя (6) будем иметь:

$$
w_{q_{0}}=\xi a_{\mathrm{O}_{2}} v_{q_{0}}
$$

где $v_{q_{0}}$, Дж/(с · моль), определяется выражением (14), то есть имеем:

$$
\begin{aligned}
w_{q_{0}} & =1322 \xi a_{\mathrm{O}_{2}}\left\{\left(-0,6 S_{\text {уд }}^{2}+235,8 S_{\text {уд }}+\right.\right. \\
& \left.\left.+9,1 \cdot 10^{4}\right) k\right\}^{0,18}\left(V^{\mathrm{\Gamma}}\right)^{0,5} .
\end{aligned}
$$

Итак, согласно полученному выражению скорость тепловыделения $w_{q_{0}}$ есть функция удельной реакционной поверхности, концентрации кислорода, константы скорости окисления и степени метаморфизма угля.

В выражении (16) удельная реакционная поверхность $S_{\text {уд }}$ является характерной чертой каждого угля. Ее 
связь с фракционным составом изучалась автором [1] на углях разной степени углефикации в лабораторных условиях хроматографическим методом. В различных опытах уголь был измельчен до размера от $0 . .0,2$ мм до 3...3,5 мм и дегазирован. Поэтому найденная автором удельная реакционная поверхность является максимально возможной для процессов окисления.
Результаты обработки экспериментов по 27 образцам углей разной степени углефикации позволили получить ее связь с концентрацией горючих веществ в угле, представленную на рис. 1 и описываемую зависимостью

$$
\mathrm{S}_{\text {уд }}=-0,45\left(\mathrm{~V}^{\text {г }}\right)^{2}+0,18 \mathrm{~V}^{\Gamma}+44,8 .
$$

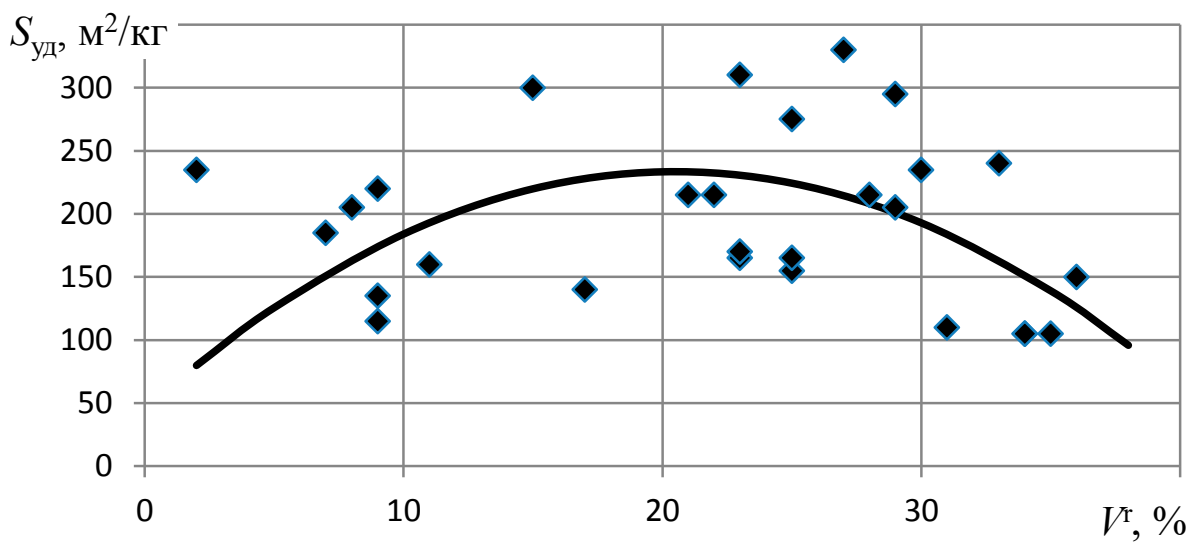

Рис. 1. Зависимость удельной реакционной поверхности угля от концентрации горючих веществ Fig. 1. Dependence between the specific reactionary surface of coal and concentration of flammable substances Источник: Собственная разработка. Source: Own elaboration.

Концентрация кислорода $a_{\mathrm{O}_{2}}$, вступающего в реакции окисления с углем на его поверхности $S_{\text {уд }}$ меняется во времени по мере проникновения кислорода в межкусковое пространство скопления угля и диффузии в поры угля. В работе [8] исследовано изменение во времени доли $\xi$ реагирующего кислорода на реакционной поверхности $S_{\text {уд }}$ и получено выражение в виде:

$$
\xi=1-\exp (-v t)+\frac{v}{\mu-v}[\exp (-\mu t)-\exp (-v t)],
$$

где $v$ - константа скорости образования поверхностного комплекса, $1 /$ ч, равная

$$
v=2,2 \cdot 10^{11} \mathrm{E}^{-3,66}
$$

$E$ - энергия активации, Дж/моль;

$\mu$ - константа скорости перехода метана из связанного состояния в свободное, $1 /$,

которую определяют из выражения:

$$
\mu=\frac{3,33 \cdot 10^{-7} J_{0}}{R^{0,2}} \exp \left(-6,66 \cdot 10^{-6}\left(V^{\mathrm{\Gamma}}\right)^{-0,3} t\right),
$$

$J_{0}$ - газоносность пласта, $\mathrm{M}^{3} / \mathrm{T}$;

$R$ - радиус частиц угля, м;

$V^{\mathrm{r}}$ - концентрация горючих веществ в угле, \%;

$t$ - время, с,

С использованием этих выражений найдем для примера скорость тепловыделения $w_{q_{0}}$, моль/(м $\left.{ }^{3} \cdot \mathrm{c}\right)$, и температуру угля за время, равное инкубационному периоду $t_{\text {инк }}$ самовозгорания, рассчитанному согласно руководящему документу [9] по шахте «Комсомолец».

Используем: $V^{\mathrm{r}}=30 \%, J_{0}=15 \mathrm{M}^{3} / \mathrm{T}, t_{\text {инк }}=600 \mathrm{ч}$, $a_{\mathrm{O}_{2}}=6,37$ моль $/ \mathrm{M}^{3} ; \xi=0,0367 ; q=7,96 \cdot 10^{5}$ Дж/моль; $a_{C}^{*}=1,14 \cdot 10^{5}$ моль $/ \mathrm{M}^{3}, k=2,77 \cdot 10^{-8} \mathrm{M}^{3} /($ с $\cdot$ моль).

Тогда согласно формуле (6) получим $w_{q_{0}}=587$ Дж/ $\left(\mathrm{M}^{3} \cdot \mathrm{c}\right)$
Примем, как было сказано выше, за величину толщины скопления угля, подверженного самонагреванию, среднее из минимальных значений $m=0,19$ м и такую же его ширину. Тогда $\Pi=0,76 \mathrm{M}, S=0,036 \mathrm{~m}^{2}$. Используя найденную для аналогичных условий в работе [10] величину $\alpha=0,41$ Дж/(c $\left.\cdot \mathrm{M}^{2} \cdot \mathrm{K}\right)$, по формуле (7) имеем: $T_{\text {кр }}=355 \mathrm{~K}$.

Выполним аналогичный расчет, используя зависимость для определения удельной реакционной поверхности угля и ее связь с величиной $a_{C}^{*}(14)$.

Согласно (17) имеем: $S_{\text {уд }}=192 \mathrm{~m}^{2} /$ кг. По формуле (16) находим $w_{q_{0}}=601$ Дж/( $\left.\mathrm{M}^{3} \cdot \mathrm{c}\right)$. Температура угля по формуле (7) для этого случая: $T_{\text {кр }}=367 \mathrm{~K}$.

Найденная лабораторным путем критическая температура самовозгорания этого угля составила $362 \mathrm{~K}$. Таким образом, расчетное значение $T_{\text {кр }}$ довольно близко к лабораторному, что свидетельствует о верности предлагаемого метода расчета температуры в скоплении угля по убыли кислорода, вступившего в реакции окисления.

С целью подтверждения достоверности использования данных газового состава для расчета температуры очага самонагревания угля воспользуемся результатами автора [1] по 27 случаям исследования углей в лабораторных условиях. Анализируемые угли представляли весь спектр их углефикации от длиннопламенных до антрацитов, критические температуры самовозгорания составляли от 358 до 390 К, константы скорости реакции окисления при критических температурах - от $8 \cdot 10^{-4}$ до $90 \cdot 10^{-4} 1 / \mathrm{c}$, удельные реакционные поверхно-

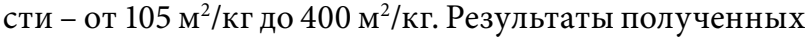
зависимостей температуры угля от израсходованного на реакции его окисления кислорода для углей марки Ж представлены на рис. 2. 


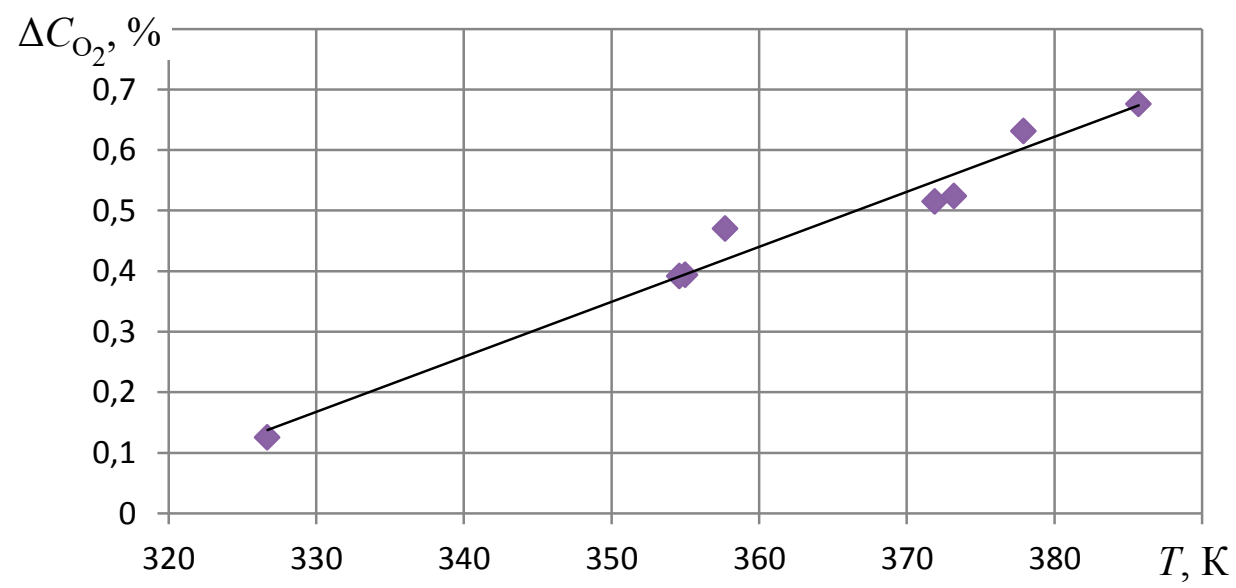

Рис. 2. Зависимость температуры угля марки Ж от концентрации кислорода, израсходованного на его окисление Fig. 2. Dependence between the temperature of $\mathrm{Zh}$ rank coal and the concentration of the oxygen used for its oxidation Источник: Собственная разработка. Source: Own elaboration.

Из анализа представленных на рисунке данных следует, что в изученном диапазоне температур их зависимость от израсходованного на реакции окисления кислорода может быть принята линейной

$$
\Delta C_{\mathrm{O}_{2}}=0,01 T-2,83
$$

и полностью соответствует предложенной теоретической зависимости (7). Выражение для определения температуры угля имеет вид:

$$
T=111,1 \Delta C_{\mathrm{O}_{2}}+314,4 .
$$

С целью возможности использования полученных результатов для условий горных выработок, где израсходованный на реакции окисления угля кислород подвергается разбавлению воздухом аварийного участка, необходимо учитывать еще один компонент газового состава продуктов окисления угля для нахождения температуры очага пожара. В качестве такового компонента используем оксид углерода, довольно точно определяемый в шахтных условиях экспресс методом и практически не поглощаемый углями, породами и шахтными водами. Найдем зависимость $T=f\left(C_{\mathrm{CO}} / \Delta C_{\mathrm{O}_{2}}\right)$, в которой $C_{\mathrm{CO}}-$ концентрация оксида углерода на исходящей из пожарного участка струе воздуха, \%, а $\Delta C_{\mathrm{O}_{2}}$ - разность концентраций кислорода на свежей и исходящей струе воздуха, \%.

Отношение $C_{\mathrm{CO}} / \Delta C_{\mathrm{O}_{2}}$ для каждого типа угля находится в лабораторных условиях газодинамическим методом путем пропускания кислорода через слой угля с такой же скоростью, которая характерна для условий его самонагревания в шахтах, т.е. порядка $1 \cdot 10^{-5} \div 1 \cdot 10^{-4}, \mathrm{M} / \mathrm{c}$.

Воспользуемся теоретическими и экспериментальными данными динамики параметров окисления угля марки Ж, приведенными выше и экспериментальными данными авторов [11], изучавших склонность углей к самонагреванию, из которых получим результаты, представленные в таблице 1 .

Таблица 1. Расчетные данные динамики параметров окисления углей марки Ж

Table 1. Calculation data of dynamics of oxidation characteristics of $\mathrm{Zh}$ rank coals

\begin{tabular}{|l|c|c|c|c|c|c|c|}
\hline & \multicolumn{7}{|c|}{ Время, ч / Time, h } \\
\hline $\begin{array}{c}\text { Параметр / } \\
\text { Parameter }\end{array}$ & 530 & 550 & 580 & 620 & 650 & 670 & 700 \\
\hline$a_{\mathrm{O}_{2}}$, моль/м3 & 5,9 & 6,05 & 6,12 & 0,19 & 6,25 & 6,6 & 6,9 \\
\hline$\xi$ & 0,030 & 0,033 & 0,036 & 0,038 & 0,041 & 0,043 & 0,045 \\
\hline $\mathrm{T}, \mathrm{K}$ & 340 & 350 & 360 & 370 & 380 & 390 & 400 \\
\hline$\Delta C_{\mathrm{O}_{2}}, \%$ & 0,23 & 0,32 & 0,41 & 0,50 & 0,59 & 0,68 & 0,77 \\
\hline$C_{\mathrm{CO}} \%$ & $0,005^{*}$ & 0,01 & 0,016 & 0,030 & $0,053^{*}$ & 0,088 & 0,154 \\
\hline * - по данным (according to data) [11] & & & & & \\
\hline
\end{tabular}

Из анализа результатов следует, что по мере окисления угля возрастает содержание оксида углерода и израсходованного на окисление кислорода, поэтому представляет интерес установить взаимосвязь температуры угля с отношением $C_{\mathrm{CO}} / \Delta C_{\mathrm{O}_{2}}$ (рис. 3). 


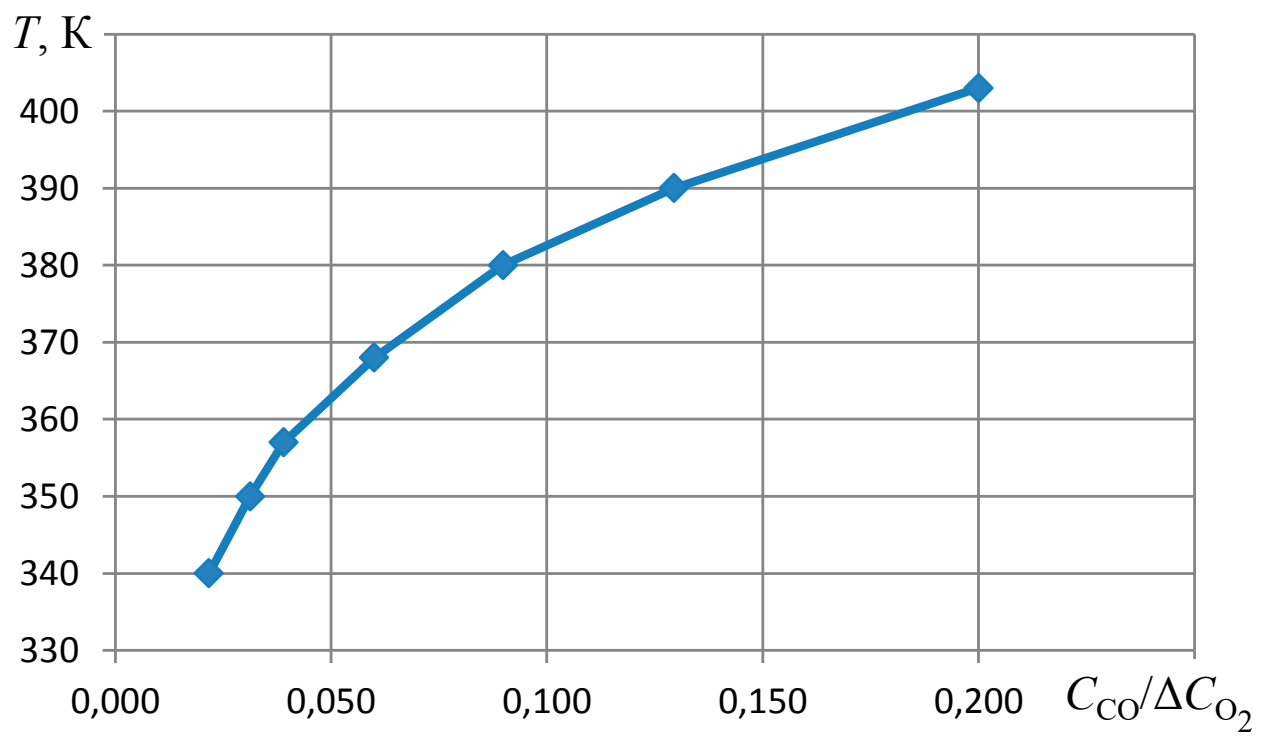

Рис. 3. Зависимость температуры самонагревания угля от соотношения $C_{\mathrm{CO}} / \Delta C_{\mathrm{O}_{2}}$ Fig. 3. Relationship between coal spontaneous heating temperature and $C_{\mathrm{CO}} / \Delta C_{\mathrm{O}_{2}}$ ratio Источник: Собственная разработка.

Source: Own elaboration.

Аналитическое выражение этой зависимости может быть представлено видом:

$$
\mathrm{T}=456\left(\frac{\mathrm{C}_{\mathrm{CO}}}{\Delta \mathrm{C}_{\mathrm{O}_{2}}}\right)^{0,076}
$$

\section{3. Апробация}

Для апробации предложенного подхода к определению температуры самоокисления углей было выполнено сравнение результатов вычисления температуры на аварийном участке по соотношению концентраций $C_{\mathrm{CO}} / \Delta C_{\mathrm{O}_{2}}$ и по соотношению концентраций непредельных углеводородов (этилена и ацетилена) $C_{\text {эт }} / C_{\text {ац. }}$ Результаты приведены в таблице 2.

Таблица 2. Сопоставление результатов расчета температуры по различным индикаторным компонентам Table 2. Comparison of results of temperature calculation according to various indicator components

\begin{tabular}{|c|c|c|c|}
\hline Шахта / Mine & $\begin{array}{c}\text { Марка угля / } \\
\text { Туре of coal }\end{array}$ & $\begin{array}{c}\text { Температура по соотношению } \\
\text { концентраций } C_{\mathrm{Co}} / \Delta C_{\mathrm{O}_{2}}, \mathrm{~K} \\
\text { / Temperature according to the } \\
\text { ratio of concentrations } \\
C_{\mathrm{CO}} / \Delta C_{\mathrm{O}_{2}}, \mathrm{~K}\end{array}$ & $\begin{array}{c}\text { Температура по } \\
\text { соотношению концентраций } \\
C_{\text {эт }} / C_{\text {ац }}, K / / \text { Temperature } \\
\text { according to the ratio of } \\
\text { concentrations } C_{\text {эт }} / C_{\text {ац }}, K /\end{array}$ \\
\hline $\begin{array}{l}\text { “Пионер» ОOО «Добропольеуголь» } \\
\text { / “Pioner” PAO DTEK “Dobropolyeugol” }\end{array}$ & ДГ & 334 & 333 \\
\hline \multirow{3}{*}{$\begin{array}{l}\text { «им. Артема» } \\
\text { ГП «Луганскуголь» } \\
\text { / "Artyom Mine” } \\
\text { "GP Luganskugol” }\end{array}$} & \multirow{3}{*}{$\mathrm{T}$} & 355 & 403 \\
\hline & & 395 & 363 \\
\hline & & 417 & 433 \\
\hline \multirow{2}{*}{$\begin{array}{l}\text { «Комсомолец Донбасса» ПАО ДТЭК } \\
\text { / PAO DTEK Shachta Komsomolets } \\
\text { Donbassa }\end{array}$} & \multirow{2}{*}{$\mathrm{T}$} & 471 & 473 \\
\hline & & 453 & 473 \\
\hline
\end{tabular}

Источник: Собственная разработка.

Source: Own elaboration.

Из анализа данных табл. 2 следует, что температуры, определенные по двум соотношениям имеют близкие значения. Различие в некоторых случаях можно объяснить различной газоносностью пластов и степенью углефикации угля. Таким образом, предложенный метод определения температуры самонагревания угля по соотношению $C_{\mathrm{CO}} / \Delta C_{\mathrm{O}_{2}}$ может быть использован для начальной стадии процесса окисления. 


\section{Аббревиатуры}

\begin{tabular}{|c|c|c|}
\hline$t$ & время & c \\
\hline$J_{0}$ & газоносность пласта, & $\mathrm{M}^{3} / \mathrm{T}$ \\
\hline$l$ & длина зоны горения & M \\
\hline$\xi$ & доля концентрации кислорода, вступающая в реакции окисления с углем & - \\
\hline$t_{\text {инк }}$ & инкубационный период самовозгорания & ч \\
\hline$q$ & интенсивность источника тепла при горении & $\mathrm{BT} / \mathrm{M}^{3}$ \\
\hline$w_{q_{0}}$ & интенсивность тепловыделения & Дж/( $\left.\mathrm{M}^{3} \cdot \mathrm{c}\right)$ \\
\hline$v$ & константа скорости образования поверхностного комплекса & $1 / 4$ \\
\hline$\mu$ & константа скорости перехода метана из связанного состояния в свободное & $1 / ч$ \\
\hline$k$ & константа скорости окисления & $\begin{array}{l}1 / \mathrm{c} ; \\
\mathrm{M}^{3} /(\mathrm{c} \cdot \text { моль })\end{array}$ \\
\hline$C_{0}$ & концентрация кислорода на входе в зону горения & $\%$ \\
\hline$C_{1}$ & концентрация кислорода на выходе из зоны горения & $\%$ \\
\hline$a_{\mathrm{O}_{2}}$ & концентрация кислорода & моль/м \\
\hline$a_{\mathrm{C}}^{*}$ & концентрации углерода & моль $/ \mathrm{M}^{3}$ \\
\hline$C_{\mathrm{CO}}$ & концентрация оксида углерода на исходящей струе воздуха & $\%$ \\
\hline$C_{\mathrm{aц}}$ & концентрация ацетилена & $\%$ \\
\hline$C_{\text {эт }}$ & концентрация этилена & $\%$ \\
\hline$V^{\mathrm{r}}$ & концентрация горючих веществ в угле & $\%$ \\
\hline a & коэффициент теплообмена между скоплением угля и окружающими его породами & $\mathrm{BT} /\left(\mathrm{M}^{2} \cdot \mathrm{K}\right)$ \\
\hline$\tilde{u}$ & массовая скорость воздуха & $\mathrm{M} / \mathrm{c}$ \\
\hline$\rho$ & плотность газа & $\kappa \Gamma / \mathrm{M}^{3}$ \\
\hline$\rho_{0}$ & плотность газа при температуре $T_{0}$ & $\mathrm{\kappa} / \mathrm{M}^{3}$ \\
\hline$S$ & площадь поперечного сечения скопления угля & $\mathbf{M}^{2}$ \\
\hline$\Pi$ & периметр скопления угля & M \\
\hline$R$ & радиус частиц угля & M \\
\hline$\Delta C_{\mathrm{O}_{2}}$ & разность концентраций кислорода на свежей и исходящей струе воздуха & $\%$ \\
\hline$u$ & скорость движения воздуха & $\mathrm{M} / \mathrm{c}$ \\
\hline$v_{q_{0}}$ & скорость тепловыделения & Дж/(с· моль) \\
\hline$T$ & температура в очаге пожара & K \\
\hline$T_{0}$ & температура до пожара & K \\
\hline$T_{c}$ & температура пород, окружающих скопление угля & K \\
\hline$H_{c}$ & теплота сгорания твердого материала & Дж/кг \\
\hline$q_{0}$ & теплота реакции окисления & Дж/моль \\
\hline $\bar{q}$ & удельная интенсивность тепловыделения в зоне горения & $1 / \mathrm{c}$ \\
\hline $\bar{\alpha}$ & удельный коэффициент теплообмена скопления угля с окружающими его породами & $\mathrm{M} / \mathrm{C}$ \\
\hline$S_{\text {уд }}$ & удельная поверхность угля & $\mathrm{M}^{2} / \mathrm{K \Gamma}$ \\
\hline$c$ & удельная теплоемкость газов при постоянном давлении & Дж/(кг · К) \\
\hline$E$ & энергия активации & Дж/моль \\
\hline
\end{tabular}

\section{Литература}

[1] Pashkovskiy P.S., Engogennye pozhary v ugolnykh shakhtakh, Knowledge, Donetsk 2013, 791.

[2] Kucher R.V., Kompanets V.A., Butuzova L.F., Struktura iskopaemykh uglei i ikh sposobnost k okisleniiu, Nauk. Dumka, Kiev 1980, 168.

[3] Lindenau N.I., Maevskaya V.M., Krylov V.F., Proiskhozhdenie i tushenie engogennykh pozharov $v$ ugolnykh shakhtakh, M.: Nedra, 1977, 320.
[4] Grekov S.P., Cygankiewicz J., Koshovskiy B.I., Berezovskiy A.A., Neizotermicheskaiya kinetika geterogennogo okisleniya uglei kislorodom vozdukha $i$ ikh samonagrevaniia, "Khimiya tverdogo topliva" Issue 6, 2000, pp. 27-37.

[5] Draizdel D., Vydelenie v dinamiku pozharov, Stroiizdat, 1990, 424. 
[6] Grekov S.P., Orlikova V.P., Vsiakii A.A., Opredelenie sklonnosti uglei k samovozgoraniiu, „Gornospasatelnoe delo: sb. nauch. tr." Vol. 51, pp. 88-99.

[7] Grekov S.P., Pashkovskiy P.S., Orlikova V.P., Teplovoi effekt okisleniia uglia i engogennaia pozharoopasnost, „Ugol Ukrainy" Issue 10, 2014, pp. 46-50.

[8] Pashkovskiy P.S., Grekov S.P., Zinchenko I.N., Aktualnye voprosy borby c samovozgoraniem uglia, Arpi, Donetsk 2013, 655 .
[9] Rukovodstvo po preduprezhdeniiu i tusheniiu endogennykh pozharov na ugolnykh shakhtakh Ukrainy: КД 12.01.402-2000, NIIGD „Respirator”, Donetsk 2001, 215.

[10] Grekov S.P., Pashkovskiy P.S, Vsiakii A.A., Inzhenernyi metod opredeleniia inkubatsionnogo perioda samovozgoraniia uglia, „Ugol Ukrainy” Issue 3, 2015, 4.

[11] Münzner V.H., Peters W., Zur Kinetik der Kohleoxydation im Temperaturbereich $30^{\circ} \mathrm{C}-100^{\circ} \mathrm{C}$. Eingegangen am 26 . August 1965, 399-407.

Греков Святослав Павлович - доктор технических наук, член-корреспондент Международной академии наук высшей школы, заместитель заведующего отделом борьбы с эндогенными пожарами в шахтах и на породных отвалах, специалист в области тепломассопереноса в горных выработках и пористых средах.

Пашковский Петр Семенович - доктор технических наук, профессор, заслуженный деятель науки и техники Украины, первый заместитель директора НИИГД „Респиратор”, основатель научной школы борьбы с пожарами на угольных шахтах.

Орликова Виктория Петровна - окончила Донецкий национальный университет по специальности химик. Научный сотрудник отдела борьбы с эндогенными пожарами в шахтах и на породных отвалах НИИГД „Респиратор”. Имеет более 20 публикаций в научно-технических изданиях, является соавтором 12 национальных стандартов и 4 патентов. 